\title{
DiReito E SAÚde MENTAL
}

Dyrceu Aguiar Dias Cintra Junior ${ }^{(*)}$

\section{RESUMO}

O texto trata da assistência aos portadores de transtornos mentais. Traça breve histórico da legislação sobre o assunto, relata os avanços obtidos pela chamada luta antimanicomial no Brasil, analisa as novidades introduzidas pela Lei n. 10.216, de 6-4-2001, que define um novo modelo assistencial em saúde mental, e, por fim, preconiza mudanças na legislação civil, penal e trabalhista para adequá-las ao novo modelo e aos Princípios para a proteção de pessoas acometidas de transtorno mental e para a melhoria da assistência à saúde mental da ONU.

\section{Abstract}

The paper is about the assistence to the mentally ill. Traces a brief history of the legislation about the issue, relates the improvement of the movement against the insane asylum model, analyses the news introduced by the Law $n$. 10.216, of 6-4-2001, that defines a new assistencial model in mental health, and, in the end, commends publicly changes in the civil, criminal and labour legislation in order to adequate them to the new model and the Principles for the protection of persons with mental illness and the improvement of mental health care of ONU.

\section{Palavras-chave}

Saúde mental, Estabelecimento psiquiátrico, Internação, Reforma psiquiátrica. Legislação sobre portadores de transtornos mentais.

\section{Key words}

Mental health, Psychiatric hospital, Psychiatric reform, Legislation about mentally ill.

(*) Juiz no $2^{2}$ Tribunal de Alçada Civil do Estado de São Paulo. Membro da Associação Juizes para a Democracia. Membro do Instituto Brasileiro de Ciências Criminais. 


\section{INTRODUÇÃO: A HISTÓRIA DA EXCLUSÃO}

As origens mais remotas da legislação sobre a loucura estão, certamente, vinculadas à idéia de segregação, ou, mais precisamente, de autorização legal para que o Estado isolasse o portador de distúrbio mental.

Até a Revolução Francesa, não havia ainda a conceituação do "louco" enquanto doente mental. É com a psiquiatria, no final do século XVIII, que a loucura ganha status de doença, em decorrência, sobretudo, de ter ela se tornado um problema social nas cidades da Europa, cada vez mais populosas.

A prática do isolamento pode ser notada na época do Renascimento.

Havia, na Europa renascentista, o costume de se confinar os "loucos" num navio que vagava de porto em porto, sem destino. Note-se o sentido simbólico disso: os insanos embarcavam numa viagem infindável, sem ponto de chegada; o exílio ritual; eram prisioneiros de sua própria partida. ${ }^{(1)}$

A "nau dos loucos" não encerrava só perturbados mentais, está claro. Nela havia lugar para os bêbados, os devassos, os desordeiros, os que "interpretavam mal as escrituras", os blasfemadores. A loucura era abordada a partir de um exclusivo sentido moral.

Assim tambem foram os hospitais gerais criados na França por ordem do rei - a partir de 1656, com a fundação por decreto do Hospital Geral de Paris - com o objetivo de aprisionar não apenas a loucura, mas todos os pobres da cidade. Por isso, no dizer de Foucault, o hospital geral não tem caráter médico, senão de uma "estrutura semijurídica, uma espécie de entidade administrativa que, ao lado dos poderes já constituídos, e além dos tribunais, decide, julga e executa", dirigida por diretores nomeados para toda a vida: um poder estabelecido pelo rei entre a polícia e a justiça. ${ }^{(2)}$

Muitos antigos leprosários na Idade Média foram reativados, nessa época, pelo clero $€$ por mando real, com o objetivo de ordenar a miséria que grassava pela Europa. Em muitos desses hospitais gerais, casos mais extremos de alienação mental eram tratados com confinamento em jaulas, relegando homens à condição de animais, como descrito em diversas obras literárias. A exploração da mão-de-obra em tais instituições era fato comum.

(1) João Fraize-Pereira, O que é loucura, São Paulo, Brasiliense, 1986, p. 51.

(2) Como revela Foucault, "é sabido que o século XVII criou vastas casas de internmento; não é muito sabido que mais de um habitante em cada cem da cidade de Paris viu-se fechado numa delas, por alguns meses. É bem sabido que o poder absoluto fez uso das cartas régias e de medidas de prisão arbitrárias; é menos sabido qual a consciência jurídica que poderia animar essas práticas" (História da Loucura, apud João Frayse-Pereira, ob. cit., p. 62). Sobre isso, também, vide Hélio Lauar, Pensando a Internaçāo, em Lei Carlão em debate, 1995, p. 49. 
A Revolução Francesa procurou dar um caráter "científico" àquele isolamento, dentro do espírito do novo regime, desenvolvendo institutos jurídicos inspirados nos valores burgueses que se instalavam, sobretudo com base na Declaração dos Direitos do Homem e do Cidadão, que estabelece a assistência pública como uma dívida sagrada.

O internamento ganhou valor terapêutico e virou o asilo de Philippe Pinel, médico francês. Este construía em torno dos portadores de transtorno mental um círculo invisível de julgamentos morais: a observação para criar um rigoroso controle ético.

Entendia necessários ao tratamento: 1) o isolamento para romper com o foco permanente de influências incontroladas que é a vida social; 2) o estabelecimento da ordem asilar; 3) uma relação de autoridade entre o médico e seus auxiliares e o doente. Sob estes três princípios foi instituído o manicômio-hospitalar para tratamento mental. ${ }^{(3)}$

No mesmo período, na Inglaterra, Tuke dirigia experiência semelhante, calcada numa comunidade religiosa, para submeter o internado a um controle simultaneamente social e moral. ${ }^{(4)}$

\section{MODELO EXISTENTE}

De fins do século passado a este século, significativas descobertas foram feitas a influírem no tratamento psiquiátrico: a psicanálise de Freud e a psicofarmacoterapia.

Mas, apesar disso, os estabelecimentos de internação pouco mudaram. A ética da exclusão social do enfermo mental ainda vigora. Tal exclusão implica: 1) a exclusão jurídica (pela interdição); 2) a exclusão nos assuntos do círculo familiar (os segredos, os pactos de dependência, a vergonha, a construção permanente de fracassos); 3) a exclusão no trabalho (a aposentadoria por doença incapacitante, a noção de emprego "de favor"); 4) a exclusão no processo educacional (o estigma das classes especiais ou do apontamento pelos colegas da situação de hipossuficiência); 5) a exclusão terapêutica (hospitais psiquiátricos).

Os manicômios continuam sendo a ponta mais aguda do processo de exclusão. São uma estrutura de completo desrespeito aos direitos fundamentais da pessoa humana.

(3) Ana Maria Fernandes Pitta e Sueli Gandolfi Dallari, A cidadania dos doentes mentais no sistema de saúde do Brasil, em Saúde em debate, n. 36, 1992, p. 19.

(4) João Frayse-Pereira, ob. cit., pp. 83/86. 
Os objetivo:s centrais do asilo pineliano continuam vivos, no Brasil, por força do velhíssimo Decreto n. 24.559/34, que tratava da questão no âmbito nacional até a edição da recente Lei n. 10.216/2001.

O modelo clue temos, reproduzindo conceitos legais até há pouco vigentes, procura marcar bem a diferença entre "normal" e "anormal". A prática decorrente de sua aplicação não destoa muito da nau referida no início do trabalho: a internação constitui, para o enfermo mental, quase sempre, uma porta de entrada, nunca de saída.

Para que se tenha uma idéia do modelo sustentado pelo referido decreto, basta que se constate quantas vezes aparece em seu texto a palavra "estabelecimento psiquiátrico". Por ele, "a profilaxia mental, [...] assistência e proteção [...] dos psicopatas" - que é objetivo enunciado no preâmbulo parece ter um só nome: "estabelecimento psiquiátrico". ${ }^{(5)}$

Especialistas que preconizam uma nova ética sobre a doença mental têm denunciado, a par do isolamento físico dos internados, o uso abusivo dos psicotrópicos e a atuação exclusiva na doença em detrimento de outras dimensões do ser humano, que o portador de transtorno mental não as perde.

Não são poucos os casos de pessoas que, internadas por sofrerem de doenças como epilepsia, enxaqueca, podem ter "enlouquecido" mesmo é no hospício.

Há dados avaliativos reveladores de que apenas aproximadamente $12 \%$ dos internados deveriam permanecer nas instituições.

\section{LUTA ANTIMANICOMIAL NO BRASIL}

A aniquilação do indivíduo portador de problemas mentais em seus mais elementares direitos de cidadania gerou o questionamento do modelo tradicional, em nível técnico, à luz da experiência científica contemporânea, e deu origem a movimento pela reforma da legislação psiquiátrica.

O objetivo é respeitar os direitos humanos do doente mental, submetendo-o a um novo complexo de intervenções, em que a preocupação com a pessoa humana dele é a central.

(5) Segundo o Decreto n. 24.559/34, do governo provisório de Getúlio Vargas, dentre outras coisas, "Sempre que, por qualquer motivo, for inconveniente a conservação do psicopata em domicilio, será o mesmo removido para estabelecimento psiquiátrico" (artigo $9^{\circ}$ ). Dele consta também que, "O psicopata ou o indivíduo suspeito de atentar contra a própria vida ou a de outrem, que perturbar a ordem ou olender a moral pública, deverá ser recolhido a estabelecimento psiquiátrico" (artigo 10). 
Depois de demorada tramitação legislativa, foi finalmente aprovado o projeto do Deputado Paulo Delgado, surgido na esteira da luta antimanicomial com o propósito de reformar significativamente a assistência psiquiátrica, em nível nacional.

Infelizmente, a internação involuntária não foi abolida, podendo ocorrer mesmo sem ordem judicial. Mas a nova lei traz avanços na linha alternativa à internação hospitalar.

Antes, em diversos Estados, o assunto já havia avançado significativamente.

Em São Paulo, os princípios básicos da reforma psiquiátrica estão no artigo 33 do Código de Saúde do Estado (Lei Complementar à Constituição Paulista). Há, no caput do referido artigo, a diretriz de superação gradativa do procedimento de internação hospitalar, no tocante à saúde mental. Outras inovações relacionadas com o pleito por reformas antimanicomiais estão nos incisos III (a previsão de tratamento em ambiente menos restritivo possível e o consentimento informado), IV (a internação como último recurso terapêutico) e VI (a vigilância dos direitos indisponíveis do indivíduo assistido de forma articulada com a autoridade sanitária e o Ministério Público).

Em Minas Gerais, a Lei n. 11.802/95, chamada "Lei Carlão", também tratou adequadamente a promoção da saúde do portador de sofrimento mental, incorporando dispositivos do direito internacional (Princípios para a proteção de pessoas acometidas de transtorno mental e para a melhoria da assistência à saúde mental, da ONU, de 1991) e recomendações do Relatório final da 2ª Conferência Nacional de Saúde Mental, realizada em 1994.

A lei mineira, dentre outras inovações $\left.{ }^{(6)}: 1\right)$ dá ênfase ao direito ao tratamento para reinserção social (artigo $1^{\circ}$ ), considerando, quando possível, a vontade do paciente (artigo $4^{\circ}{ }^{\circ}$ IV) ${ }^{(7)} ; 2$ ) bane o modelo centrado na exclusão, inclusive no ensino (artigo 16), e resgata, como fator auxiliar do tratamento, a reinserção na família, no trabalho e na comunidade ${ }^{(8)}$; 3) prevê serviços de saúde mental substitutivos dos hospitais psiquiátricos, a serem gradativamente extintos (artigo 21 ); 4) vincula os poderes públicos estadual e municipais à implementação de um novo sistema, alternativo aos hospitais psiquiátricos - ambulatórios, serviços de emergência psi-

(6) Todas também constantes do projeto paulista - Projeto de Lei n. 366 -, em tramitação desde 1992.

(7) Trata-se, aqui, de incorporação do $11^{9}$ dos Princípios para a proteção de pessoas acometidas de transtorno mental e para a melhoria da assistência à saúde mental, da ONU, de 1991, que prevê o consentimento informado e a formas de supri-lo em casos excepcionais.

(8) O direito à vida e ao trabalho em comunidade, sempre que possivel, é destacado no Princípio $n$. 3 do referido instrumento internacional. O Princípio $n$. 7 fala, ainda, do papel de comunidade e da cultura no tratamento. 
quiátrica em prorito-socorros gerais e centros de referência, leitos em hospitais gerais, serviços de hospital-dia e hospital-noite, centros de referência em saúde mental, centros de conveniência, lares e pensões protegidas (artigos $2^{\circ}$ e $3^{\circ}$ ); 5) bane procedimentos desumanos como a camisa-deforça, cela-forte $\Theta$ outros (artigo $5^{\circ}$ ) e regulamenta minuciosamente as práticas terapêuticas psiquiátricas biológicas (artigo 4ำ, parágrafo único), nas quais se incluem a eletroconvulsoterapia, o choque cardiazólico e o choque insulínico, tidos como de aplicação abusiva, até aqui(9); 6) proíbe as psicocirurgias e quaisquer procedimentos que impliquem efeitos orgânicos irreversiveis a título de tratamento da enfermidade mental(10) (artigo 6o); 7) prevê a internação como último recurso (artigo $9^{\circ}$ ), vinculando-a à existência de laudo médico especializado com diagnóstico, autorização da família ou paciente e previsão de tempo de tratamento (artigo 10); 8) prevê a separação dos portadores de síndrome de dependência alcoólica em leito de clínica médica, em hospitais gerais ou pronto-socorros gerais (artigo 9ㅇ, $\S 2^{\circ}$ ) e a intervenção necessária do Ministério Público e da autoridade sanitária local (artigos 12 e 13).

\section{LEI N. $10.216 / 2001$}

A lei de âmibito nacional recentemente aprovada proíbe a internação em "instituições com características asilares", ou seja, aquelas desprovidas de serviços médicos, psicológicos, ocupacionais, de assistência social, de lazer e outros ( $\left(2^{\circ}\right.$ do artigo $4^{\circ}$ ), e que não assegurem ao paciente os direitos básicos do sistema.

Tais direitos básicos da pessoa enferma são: I - ter acesso ao melhor tratamento do sistema de saúde, consentâneo às suas necessidades; II - ser tratada com humanidade e respeito e no interesse exclusivo de beneficiar sua saúde, visando a alcançar a sua recuperação pela inserção na família, no trabalho e na comunidade; III - ser protegida contra qualquer forma de abuso e exploração; IV - ter garantia de sigilo nas informações prestadas; V - ter direito à presença médica, em qualquer tempo, para esclarecer a necessidade ou não de sua hospitalização involuntária; VI - ter livre acesso aos meios de comunicação disponíveis; VII - receber o maior número de informações a respeito de sua doença e de seu tratamento; VIII - ser tratada em ambiente terapêutico pelos meios menos invasivos possíveis; IX - ser tratada, preferencialmente, em serviços comunitários de saúde mental (parágrafo único do artigo $2^{\circ}$ ).

(9) A forma de preservar o respeito à dignidade da pessoa acometida de transtorno mental está no Princípio $n .11$ daquele documento.

(10) A limitação radical da psicocirurgia está no item 14 do Princípio n. 11 do documento. 
Prevê a lei, também, a necessidade de autorização médica para qualquer tipo de internação e a notificação compulsória ao Ministério Público, no prazo de 72 horas, nos casos em que o internamento se dê contra a vontade do paciente.

\section{DESAFIOS PARA IMPLEMENTAÇÃO DO NOVO MODELO}

Há necessidade de desenvolver políticas públicas tendentes à perfeita aplicação da nova lei.

Um dos primeiros problemas com que deparamos diz respeito às internações já existentes.

O assunto está a demandar uma ampla verificação pelo Ministério da Saúde e outros órgãos, aos quais a Lei n. 10.216/2001 atribui funções, no sentido de adequar as internações em curso à nova legislação, verificando sua necessidade e implementando os controles previstos. sistema.

Não se pode esquecer que o sentido da lei é o de desconstrução de um

Depois, é preciso cuidar para que as desinternações sejam efetivamente assistidas, evitando o abandono de pessoas que necessitam de tratamento em outro ambiente. Como tem sido assinalado pelo deputado Paulo Delgado, autor do projeto, as vagas de hospital psiquiátrico devem ser bloqueadas apenas mediante a criação de vagas correspondentes no serviço aberto (centros de atenção psicossocial, núcleos, pensões protegidas, lares abrigados, o hospital-dia, o hospital-noite, ala psiquiátrica de hospital geral, emergência psiquiátrica, serviço psiquiátrico no posto de saúde da periferia).

Outra questão importante é a de ordem cultural. A aplicação efetiva da lei exige uma mudança de mentalidade. É preciso empenhar esforços no sentido de demonstrar as vantagens de um maior contado do doente mental com a sociedade. É preciso superar preconceitos de uma população que se acostumou a pensar no doente mental como uma estranha simbiose de um ser perigoso e incapaz.

A familia deve ser objeto de atenção especial. Sabe-se que o abandono do doente mental pelos familiares se deve, em grande parte, à carência de recursos e ao peso que aquele significa. Os hospitais para doentes mentais nada mais foram, sempre, que depósitos de seres humanos, onde as familias isolavam os doentes que the pareciam inconvenientes e perigosos. Mas, se o Estado sempre pôde pagar grandes somas de dinheiro aos hospitais, por que não poderia canalizar parte desses recursos, de forma controlada, para que as famílias atendam seus doentes? 
Os transtornos mentais são responsáveis pelo terceiro maior gasto anual com internação no Sistema Único de Saúde (SUS), correspondendo atualmente a $R \$ 450$ milhões. Cerca de $95 \%$ de tal quantia ia para o modelo manicomial, remunerando internações que significavam isolamento e perda do contato social pelo paciente.

O novo regime, que investe na recuperação social, deslocando o centro da assistência do hospital para a pessoa, exige o redimensionamento na aplicação de tais recursos.

\section{MUDANÇAS LEGISLATIVAS NECESSÁRIAS}

Uma questäo que convém abordar - além da mais específica legislação sobre estabelecimentos psiquiátricos - é a das conseqüências do distúrbio mental na situação jurídica dos envolvidos, sob os enfoques das legislações civil, penal e trabalhista.

Considerando o modelo adotado pela Lei n. 10.216/2001, é preciso promover mudanças em vários pontos da legislação.

Segundo o Código Civil, dentre os absolutamente incapazes de exercer os atos da vicla civil estão os "loucos de todo o gênero", expressão esta que tem merecido críticas.

A declaração da incapacidade corresponde à chamada interdição.

O que é preciso entender, contudo, é que tal interdição visa a proteger o doente mental e não destruir seus direitos, como ocorre com freqüência.

O Decreto n. 24.559/34 já modificara parcialmente a disciplina, possibilitando ao juiz a limitação da interdição a determinados atos, incluindo o portador do distúrbio como relativamente incapaz conforme o nível de comprometimento de sua psique. De qualquer forma, a legislação ainda deixa a desejar no que se refere à cidadania do doente mental. É preciso adequá-la ao que prevê a nova lei sobre a assistência aos doentes mentais e os Princípios para a proteção de pessoas acometidas de transtorno mental e para a melhoria da assistência à saúde mental da ONU: a satisfação de necessidades compatíveis com a vida e dignidade e o perfeito acompanhamento jurídico do interditado, impondo-lhe restrições mínimas adequadas ao seu caso.

A lei penal se ressente de inadequações mais graves ainda.

Os portadores de problemas mentais podem ser tidos como: (1) inimputáveis ou (2) semi-responsáveis.

Os inimputáveis não respondem juridicamente porque não têm capacidade para sofrer juízo de censurabilidade. São isentos de pena. Os semi- 
responsáveis, por sua vez, são imputáveis, ou seja, respondem pelo fato. Mas sofrem diminuição na pena (de um a dois terços) por terem sua capacidade de discernimento diminuída.

Quais as conseqüências, para o agente, nas duas hipóteses?

A reforma penal de 1984 adotou o sistema chamado vicariante ou unitário (em oposição ao sistema do duplo binário anterior). Aplica-se a pena ou medida de segurança. Um caminho exclui o outro.

No caso de inimputável, a solução é sempre a aplicação de medida de segurança, que pode ser: 1) internação em hospital de custódia e tratamento; ou 2) tratamento ambulatorial (artigo 96 do Código Penal).

No caso do semi-responsável, o juiz pode optar entre: 1) diminuir a pena (artigo 26, parágrafo único, do Código Penal); ou 2) substituí-la por uma daquelas duas medidas de segurança, se o condenado necessitar de especial tratamento curativo (artigo 98 do Código Penal).

Ocorre que a inimputabilidade acaba tendo, em razão da lei, um tratamento muito mais penal que terapêutico. Se os estabelecimentos psiquiátricos já são ruins, calcule-se como são os manicômios judiciários.

Há mais. Segundo a lei, se o fato for apenado com reclusão, a medida de segurança será sempre de internação. Ora, e se ela for desnecessária?

Nesse ponto, a legislação penal não levou em conta o ser humano, mas o fato de que ele praticou (mais grave ou menos grave), o que choca com as exigências de internação como último recurso.

Há tempos a jurisprudência dos tribunais paulistas vem admitindo o tratamento ambulatorial, por exceção, no caso de indicação de suficiência deste no laudo que afirma a insanidade mental, abrandando, portanto, o rigor e a inadequação da lei.(11)

Outro problema reside no tempo da internação ou do tratamento ambulatorial. A lei fala em "tempo indeterminado" e prazo mínimo de três anos (artigo 97, § $\left.1^{\circ}\right)^{(12)}$ Mas, dentro da própria dogmática penal, parte da doutrina vem denunciando tal sistema como violador dos princípios constitucionais da legalidade e da igualdade. De fato, não pode haver submissão de pessoa a constrangimento - que a internação não deixa de ser —, além da pena máxima prevista para 0 delito. ${ }^{(13)}$

(11) Julgados do Tribunal de Alçada Criminal, 93/181 e 98/203; Revista dos Tribunais 634/272.

(12) Esta previsão - assim como a origem da medida de segurança - tem por base o conceito de temibilidade ou periculosidade do delinqüente com problemas mentais, no sentido de uma certa perversidade constante e ativa dele, formulado por Garofalo, penalista italiano do final do século XIX, que projetou para o Direito Penal concepçōes antropológicas e sociológicas do positivismo.

(13) Luiz Flávio Gomes, "Medidas de segurança e seus limites", em Revista Brasileira de Ciências Criminais, 2, 1993, p. 64. 
A inadequação não para aí: a disposição se choca com a nova legislação brasileira, como já se chocava, antes, com os Princípios para a proteção de pessoas acometidas de transtorno mental e para a melhoria da assistência à saúde mental, da ONU.

A Lei n. 10.216/2001 prevê o direito de acesso ao melhor tratamento, consentâneo com as suas necessidades (artigo 2, parágrafo único, l), que pode não ser a internação. A recuperação pela inserção na família é o objetivo preconizado (artigo $2^{\circ}$, parágrafo único, II), os meios de tratamento devem ser os menos invasivos (artigo $2^{\circ}$, parágrafo único, VIII) e a internação é tida como último recurso (artigo $4^{\circ}$, caput).

A lei se precicupou, ainda, em evitar ou superar a dependência institucional, que deve ser objeto de política específica de alta planejada e reabilitação psicossocial assistida (artigo $5^{\circ}$ ).

Por outro lado, o item 6 do Princípio n. 17 do documento da ONU diz que "Se, a qualquer momento, o profissional de saúde mental responsável pelo caso estiver convencido de que aquelas condições para a retenção de uma pessoa como paciente involuntário não são mais aplicáveis, este deverá determinar a alta dessa pessoa da condição de paciente involuntário".

Tais princípios se aplicam também "a pessoa cumprindo sentenças de prisão por crimes [...] e nas quais tenha sido determinada a presença de transtorno mental" (item 1 do Princípio n. 20).

Por fim, é de se destacar a inexistência de legislação trabalhista versando sobre a questão do doente mental.

Sabe-se que o trabalho é um fator importante no tratamento dos distúrbios mentais. O reconhecimento da aptidão que o doente tenha para um determinado trabalho dá-lhe autoconfiança. Mas a perspectiva de autonomia financeira mínima, que deveria corresponder à aptidão, pode ficar prejudicada pela falta de legislação específica, que não torna possível a realização de contratos de trabalho com ele.

\section{CONCLUSÃO}

Como se vê, há muita coisa ainda a ser feita para o aprimoramento da legislação sobre siaúde mental.

A Lei n. 10.216/2001 foi o começo. É claro que uma lei não faz milagres. O processo de "desinstitucionalização" deve se apoiar em condições específicas de capacitação profissional e material. E deve ter o apoio da sociedade.

Mas também não se pode falar que a lei não muda a realidade, pois, hoje, o direito tem também um sentido promocional e não apenas declarativo. 
O desenvolvimento de políticas públicas tendentes à aplicação da Lei n. 10.216/2001 pode ser cobrado inclusive por meio de ação para tutela de interesse coletivo.

A implementação adequada do novo modelo provocará mudanças institucionais e sociais. E deve servir de parâmetro para modificações legislativas quanto ao status do doente mental no âmbito do Direito Civil, do Direito Penal e do Direito do Trabalho.

$O$ assunto interessa a todos. Afinal, como dizia o grande escritor espanhol Miguel de Unamuno: "Cada um tem seu método, como cada um tem sua loucura; apenas estimamos cordato aquele cuja loucura coincide com a da maioria".

\section{BIBLIOGRAFIA}

FRAIZE-PEREIRA, João. O que é loucura. São Paulo, Brasiliense, 1986.

GOMES, Luiz Flávio. Medidas de segurança e seus limites. In Revista Brasileira de Ciências Criminais, n. 2, 1993.

LAUAR, Hélio. Pensando a Internação. In Lei Carlão em debate. Belo Horizonte, Associação Mineira de Psiquiatria e Secretaria Municipal de Saúde, 1995.

PITTA, Ana Maria Fernandes; DALLARI, Sueli Gandolfi. A cidadania dos doentes mentais no sistema de saúde do Brasil. In Saúde em debate n. 36, 1992.

. Organização das Nações Unidas. Princípios para a proteção de pessoas acometidas de transtorno mental e para a melhoria da assistência à saúde mental, São Paulo, Revista dos Tribunais, 1991, vol. 634, p. 272.

Tribunal de Alçada Criminal. Julgados do TACRIM, vol. 93/181; Julgados do TACRIM, vol. 98/203. 